\title{
More Focus
}

\section{Dear Reader,}

The results are finally in: Once again, a grand coalition will decide Germany's political fate. Meanwhile, the Federal Administrative Court has passed its verdict on diesel bans which will hopefully lend more focus to the coalition agreement and help to bring a more stringent development for mobility and energy concepts on its way. As is, the coalition agreement includes a number of familiar platitudes and provides very little information about the actual structure, but describes certain approaches which suggest that at least some intellectual manna rained down on the negotiators.

Germany is to become "world leader in the field of digital infrastructure" as a result of "the nationwide installation of gigabit networks by 2025.” This is what experts have been demanding for years, because it is the only way of ensuring the widespread use of electric vehicles and the introduction of autonomous driving on levels 4 and 5. However, the ten to twelve million euros that will be made available by 2022 will not be enough. It will also not be possible to achieve nationwide $5 \mathrm{G}$ coverage with one investment fund. By 2030 renewables should make up $65 \%$ of the country's energy consumption, primarily as a result of more offshore wind farms. Great, but the agreement is vague when it comes to important issues such as upgrading the grid and providing storage capacity. It refers to developing storage technologies by means of sector coupling and increasing the grid capacity with "new technologies and greater digitization.” However, this will mean that the Grid Expansion Acceleration Act will first have to be amended. In concrete terms, nothing will happen before 2020. Underground cabling, which is much more expensive, is first choice for grid expansion, but this is not reflected in existing budget figures.
One positive feature is that Germany will acquire a Liquefied Natural Gas (LNG) infrastructure. Importantly, Power-to-Gas (PtG) and Power-to-Liquid (PtL) are also seen as "further pillars of energy research," even though it is really a question of bringing these technologies onto the market now. By early 2019 we are to have a long overdue "future strategy for affordable and sustainable mobility.” Alongside new, more efficient and cleaner combustion engines and electric drive systems, this will also include fuel cell technology and the hydrogen infrastructure, which makes it an important step forward. One decisive factor is that in addition to highly ambitious plans to develop the charging station infrastructure, e-fuels are for the first time being seen as an important component of mobility. This is a step in the right direction, because it means taking an overall perspective. So we just need to hope that enough intelligence rains down on us from heaven to finally allow future-proof solutions to be developed for our problems.

I hope you enjoy reading this issue of ATZ.

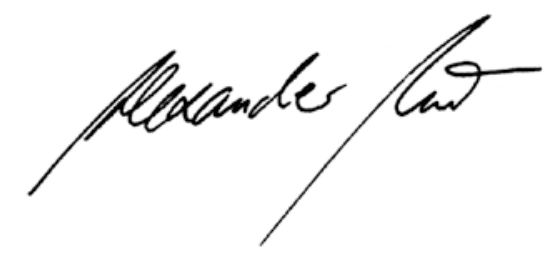

Dr. Alexander Heintzel

Editor in Chief

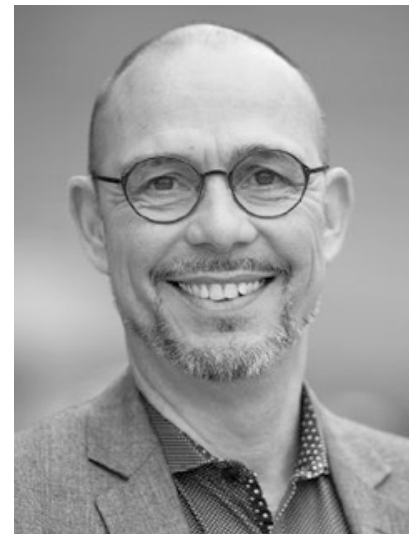

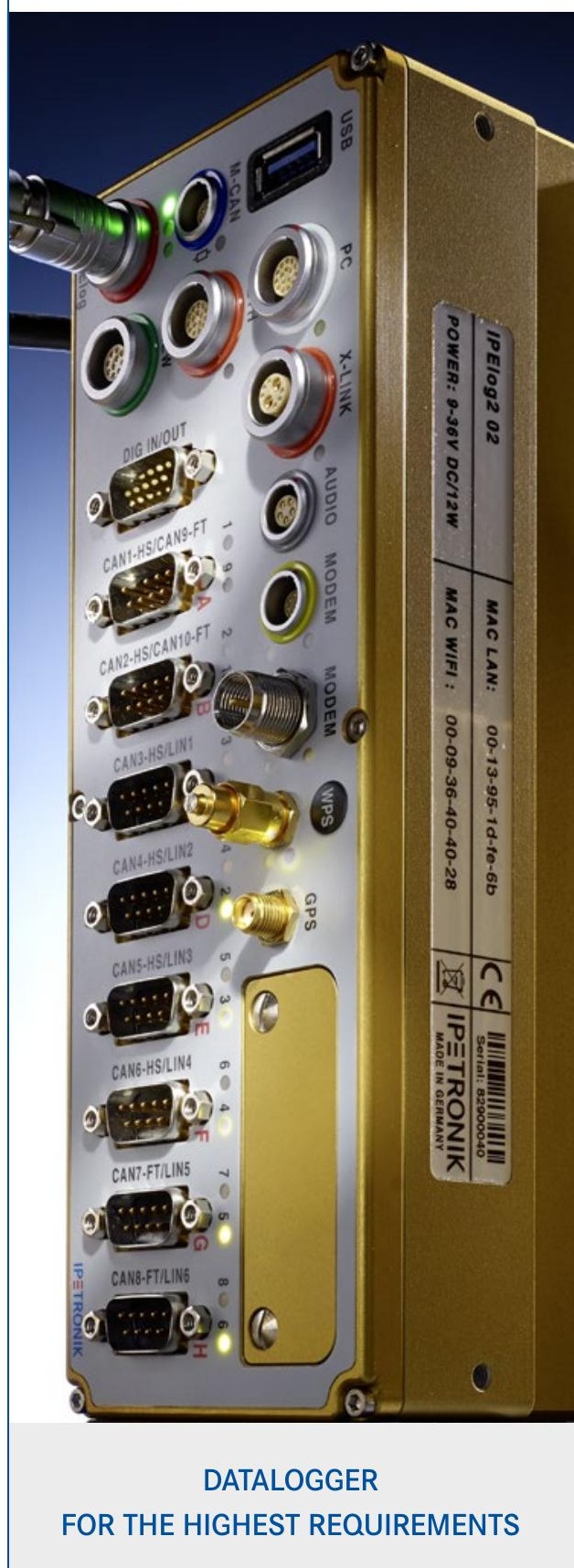

- Datalogger for fleet testing and endurance testing worldwide

- Ruggedized hardware for extreme conditions

- Ideally matched hardware and software

- Maximum reliability of data acquisition

- Proven use in hybrid and electric vehicles

- Using latest and innovative technologies 